\title{
Clinical And Genetic Study of The Sptlc1 Gene Mutation in Patients With Heridetary Sensory Neuropahty Type 1
}

\author{
Mourad $\mathrm{H}^{\mathrm{a}}$, Fadel $\mathrm{W}^{\mathrm{b}}$ and El Batch $\mathrm{M}^{\mathrm{c}}$ \\ ${ }^{a}$ Department of Clinical Pathology, ${ }^{b}$ Department of Neurology and 'Department of Biochemistry, Tanta Uni- \\ versity Hospital
}

\begin{abstract}
ABSRACT
Introduction: Hereditary sensory neuropathy type 1 (HSN1) is the most common hereditary disorder of peripheral sensory neurons. Materials and methods: This study was carried out on 15 patients with hereditary sensory neuropathy type-1 and 10 healthy individuals as a control group. Detailed family history and thorough clinical and neurological examination were performed to all patients. Nerve conduction velocity of ulnar and lateral popliteal nerves (motor and sensory) as well as audiograms was carried out for all members of the studied groups. The laboratory study included the determination of serum C-reactive protein (CRP) and serum nucleasomes as well as molecular detection of the serine palmitoytransferase (SPTLC-1) gene mutations for all studied groups. Results: There was predominance in male who developed more sever clinical manifestations than females. The disease onset was in the second and third decades of life. Patients with HSN 1 manifested reduced conduction velocity in both motor and sensory fibers of the lateral popliteal nerve $(p<0.01)$ however the ulnar nerve was spared $(p=0.61)$. Audiometry revealed bilateral partial nerve deafness in 3 cases and complete deafness in one case. Serum CRP and nucleosomes were significantly elevated in all patients as compared to the control group $(\mathrm{p}<0.01)$. The genetic study revealed mutations of the SPTLC1 in all studied patients compared to the control group. Point mutation $\mathrm{C} 133 \mathrm{~W}$ was observed in younger patients having severe clinical manifestations with prominent leg ulceration, while the point mutation C133Y was observed in the older patients complaining of hearing loss. The mutation V144D was found in patients with mild clinical presentation having minimal ulceration and no hearing abnormalities. Conclusion: The SPTLC1 gene mutations play an important role in the pathogenesis and variability in clinical presentation of HSN1 disease.
\end{abstract}

\section{INTRODUCTION}

Hereditary sensory neuropathy type 1 is the commonest hereditary disorder of peripheral sensory neurons. ${ }^{1}$ It is an autosomal dominant progressive degeneration of dorsal root ganglia and motor neurons with onset in the second or third decades. Therefore, symptoms are slowly progressive and affect the lower limbs disproportionately. Sensory loss may result in painless injuries which lead to chronic skin ulcers, predisposing to soft tissue and bone infection. ${ }^{2}$ HSN1 is clinically heterogeneous. Occasionally, patients complain of spontaneous shooting or lancinating pain. ${ }^{3}$ Deafness has been reported in some families. ${ }^{4}$ Sensorineural hearing loss is variable and when present its onset is in the middle to late adulthood. ${ }^{5}$ The expression of the disease also varies by gender within the affected individuals. The symptoms begin later in women than in men, and the progression is usually more severe in men. ${ }^{6}$ In addition to the clinical heterogeneity, HSN1

Corresponding author;

D. Heba Ahmed Mourad

Clinical Pathology

Tanta University Hospital

35 El-Nady Street, Tanta, Egypt

Email: hebamourad@hotmail.com is characterized by genetic heterogeneity, since at least three gene variants are reported. The genetic loci for two variants are defined, with linkage of HSN1 to both chromosome $9 \mathrm{q} 22$ and chromosome $3 \mathrm{q} 13-$ $22 .^{7,8}$ The genetic defect linked to the $9 q 22$ locus in the HSN1 patients is associated with missense mutations in the serine palmitoyltransferase long chain base subunit1 (SPTLC1) gene. ${ }^{9}$

Serine palmitoyltransferase (SPT) is a pyridoxal 5' phosphate dependent enzyme that catalyzes the condensation of L-serine and palmitoyl coenzyme A (CoA) to generate 3-ketodihydrosphingosine (KSD), the first committed step in de novo sphingolipid synthesis, including ceramide and sphingomyelin. 9 The enzyme is ubiquitously expressed in various tissues in mammals, and activity is primarily associated with the endoplasmic reticulum. ${ }^{10}$ The serine palmitoyltransferase enzyme consists of two subunits, SPTLC1 and SPTLC2 (also referred to as LCB1 and LCB2, respectively), both of which are required for enzyme activity. ${ }^{11} \mathrm{Ce}$ ramide produced by catabolism of sphingomyelin is known to mediate programmed cell death. ${ }^{12}$

Three mutations, C133Y, C133W, and V144D, have been identified in HSN1 patients. ${ }^{12}$ These are located within a 12-amino acid segment encoded by exons 5 and 6 of the SPTLC1 gene. ${ }^{13}$ More recently an addi- 
tional mutation has been identified in exon. ${ }^{13,14}$ These mutations are associated with increased de novo glucosyl ceramide synthesis in lymphoblast cell lines in affected individuals. Increased de novo ceramide synthesis triggers apoptosis and is associated with massive cell death during neural tube closure raising the possibility that neural degeneration in HSN1 is due to ceramide-induced apoptotic cell death. ${ }^{9,15,16}$

Ceramides are generated by serine palmitoyltransferase (SPT), the enzyme for de novo synthesis or by the action of sphingomyelinase. As lipid second messengers, they mediate antiproliferative and apoptotic effect via activation of several signal transduction molecules such as protein kinase C-alpha (PKC-a) and c-jun $\mathrm{N}$-terminal kinase (JNK). ${ }^{17}$

Cell death is one essential factor which contributes to the functional lesion. ${ }^{18}$ Circulating DNA measured in serum may be highly non specific cell death indicator and ischemic cell damage is considered to be a dynamic process affected with considerable interindividual variation. ${ }^{19}$ DNA in blood is mainly present as histon-bound nucleosomal complexes which are better conserved from further digestion by endonucleases. So, nucleosomes quantified in serum could reflect the underlying apoptotic process. ${ }^{20}$ The objective of this study is to ascertain the degree of genetic heterogeneity in a group of HSN I patients and the association between the mutation of the SPTLC1 with the clinical presentation.

\section{MATERIALS AND METHODS}

This study was carried out on 25 subjects, they were classified into two groups:

1. Patient group: Composed of 15 patients of both sexes (10 males and 5 females), their ages ranged from 14 - 46 years. All patients presented with sensory loss and/or chronic skin ulcers or painless injuries. They were selected from the outpatient clinic of Neurology Department, Tanta University Hospital. Any patient suspected or proved to have diabetes mellitus or any other causes of peripheral neuropathy was excluded from the study.

2. Control group: Composed of 10 subjects with matched age and sex.

All the studied groups were subjected to the following;

1. Detailed family history.

2. Complete clinical and neurological examination.

3. Motor nerve conduction velocities of ulnar and lateral popliteal nerves, sensory conduction velocity of ulnar and sural nerves. The apparatus used was the "DantecNeuromatic 2000C. 2 - channel".

4. Audiogram (Belotone model 110 audimeter). The criteria for selection included absence of general diseases such as diabetes mellites, hypertension and endocrine diseases and no history of ototoxic drug intake, noise exposure or otologic disorders.

5. Laboratory study : all studied groups were subjected to :

Serum CRP measurement by immuno turbidimetric test. ${ }^{21}$

Serum nucleosomes level using the cell-death-detection ELISA (Roche Diagnostics, Germany). ${ }^{22}$

Molecular genetic testing: detection of the SPTLC1 gene mutations by PCR and sequencing. ${ }^{9}$

\section{Determination of serum Nucleosome}

This assay was carried out with the cell death detection kit plus -ELISA- (Roche) as follows: $20 \mu \mathrm{L}$ of serum samples (diluted 1:4 with incubation buffer) were placed into a streptavidin-coated microtiterplate and incubated with a mixture of anti-histone-biotin and anti-DNA-POD for $2 \mathrm{~h}$ at $15-25^{\circ} \mathrm{C}$. Antibodies bind to the histones and DNA of nucleosomes and fix the immunocomplexes to the microtiterplates by the streptavidin-biotin interaction. After the incubation period, unbound antibodies are removed by washing with incubation buffer; then, the ABTS (2,2-Azino di-3ethylbenzthiazolin-sulfonate) solution is added for 30 min. Incubation of the retained POD-linked complexes with ABTS as substrate permits the spectrophotometrical quantification of the nucleosomes by measuring the absorbance at $405 \mathrm{~nm}$. As a positive control, we used the complex DNA-histone provided in the kit and as negative control, the substrate solution only. We constructed a standard curve with serial dilutions of apoptotic material ranging from 3,500 arbitrary units (AU) to 200. All determinations were performed by duplicate, and then the values were averaged. The final values expressed as (AU) were calculated after subtracting the background readings. The interassay variability was $10 \%$.

\section{Molecular study}

- DNA extraction: DNA was isolated using a commercial genomic DNA purification kit (QIAamp; QIAGEN, Valencia, CA, USA).

- $\quad$ Mutation analysis of the SPTLC1 gene: The following primers were used to amplify by PCR the SPTLC 1 at exons 5 and 6 from genomic DNA: 
exon 5, forward primer (fp) 5'-GAAATGTTT GTTTTGAACTCTTA-3' and

reverse primer (rp) 5'-AAATTGAATCTTAAC TATTGAAAG-3', resulting in product size of $195 \mathrm{bp}$.

exon 6, fp 5'-CTTGTGTTCTTTTATTTGT TCTT-3' and

rp 5'-GTCAGTATTATTTCAAAGGAACT-3' resulting in a product size of $268 \mathrm{bp}$.

- $\quad$ PCR reactions were carried out in a total reaction volume of $50 \mathrm{ul}$ (containing $10 \mathrm{mM}$ Tris- $\mathrm{Cl}, \mathrm{pH} 8.3,50 \mathrm{mM} \mathrm{KCl}, 1.5 \mathrm{mM} \mathrm{MgCl2}$, $0.2 \mathrm{mM}$ dNTPs, $100 \mathrm{ng}$ genomic DNA template, 20 pmoles each primer and $1 \mathrm{U}$ Taq DNA polymerase). Reactions were carried out with an initial denaturation at $94{ }^{\circ} \mathrm{C}$ for $5 \mathrm{~min}$, followed by 38 cycles of $94{ }^{\circ} \mathrm{C}$ for $30 \mathrm{~s}, 48{ }^{\circ} \mathrm{C}$ for $45 \mathrm{~s}, 72{ }^{\circ} \mathrm{C}$ for $1 \mathrm{~min}$, and a final extension of $10 \mathrm{~min}$ at $72{ }^{\circ} \mathrm{C}$. DNA products were separated by electrophoresis

\section{RESULTS}

This study was carried out on 15 patients with hereditary sensory neuropathy type-1 (HSN1) and 10 healthy individuals as a control group.

Table I shows that there is a male predominance $(66.7 \%)$ with onset mainly in the 2 nd and 3 rd decades

Table I. Anamnestic data of the studied groups using $2.5 \%$ agarose gel with ethidium bromide for visualization. Gel was dried and radiographed.

- $\quad$ Sequencing: The PCR products were purified with the Geneclean DNA purification Kit (BI0101). The PCR fragments were directly analyzed by ABI Prism Sequencer (Applied Biosystem Inc.) using the same primers as for amplification. Patient sequences were aligned with the control sequences to reveal the presence of mutations within the coding region of the SPTLC1 gene.

\section{Statistical analysis}

The collected data were organized, tabulated, and statistically analyzed. For quantitative data, mean \pm stander deviation (SD) were calculated, differences between means were analyzed using Student's t-tests. Pearson's correlation was used to test associations between two quantitative values, and confidence interval of $95 \%$ was adopted for significance in all used tests, where $(P \leq 0.05)$ is considered significant.

of life ( $46.6 \%$ and $53.4 \%$ respectively). Cases show ulceration of the lower limbs $(46.6 \%)$ or both lower and upper limbs (53.4\%) more frequently than the upper limbs only. Most cases had a positive family history $(86.6 \%)$ with only 2 sporadic unrelated cases $(13.4 \%)$.

HSN 1 patients $N$ (15)

\begin{tabular}{|c|c|}
\hline Age (years) & $14-46$ \\
\hline \multicolumn{2}{|l|}{ Sex : } \\
\hline Females & $5(33.3 \%)$ \\
\hline Males & $10(66.7 \%)$ \\
\hline \multicolumn{2}{|c|}{ Family history: } \\
\hline +ve & $13(86.6 \%)$ \\
\hline- ve & $2(13.4 \%)$ \\
\hline \multicolumn{2}{|c|}{ The site of trophic ulcers : } \\
\hline Upper limb & $-\quad\left(\begin{array}{ll}0 & \%\end{array}\right)$ \\
\hline Lower limb & $7 \quad(46.6 \%)$ \\
\hline Both & 8 (53.4\%) \\
\hline \multicolumn{2}{|c|}{ The onset of ulcer : } \\
\hline $2^{\text {nd }}$ decade & $7 \quad(46.6 \%)$ \\
\hline $3^{\text {nd }}$ decade & 8 (53.4\%) \\
\hline
\end{tabular}


Patients with HSN1 manifested a significantly reduced conduction velocity in both motor and sensory fibers of the lateral popliteal nerve $(p<0.01)$, however the ulnar nerve was spared $(p=0.61)$, Table II.

Table II. Sensory and motor nerve conduction velocity of the HSN 1 patients \& the control group.

\begin{tabular}{|c|c|c|c|c|c|c|}
\hline \multicolumn{7}{|c|}{ Ulnar nerve } \\
\hline & \multicolumn{3}{|l|}{ Motor } & \multicolumn{3}{|l|}{ Sensory } \\
\hline & Range & Mean & \pm SD & Range & Mean & \pm SD \\
\hline Control & $46-56$ & 51.32 & 2.98 & 46.2-53.1 & 48.32 & 1.97 \\
\hline Patients & $40-58$ & 48 & 4.89 & $38.9-51.2$ & 46.5 & 4.12 \\
\hline $\mathbf{P}$ & $0.61 \mathrm{NS}$ & & & $0.85 \mathrm{NS}$ & & \\
\hline \multicolumn{7}{|c|}{ Lateral popliteal nerve } \\
\hline & Motor & & & Sensory & & \\
\hline & Range & Mean & \pm SD & Range & Mean & \pm SD \\
\hline Control & 44-54.3 & 48.62 & 3.12 & $39-54$ & 46.72 & 4.98 \\
\hline Patients & $26-44$ & 34.9 & 6.91 & $22-38$ & 31.21 & 5.11 \\
\hline $\mathbf{P}$ & $0.01^{*}$ & & & $0.01^{*}$ & & \\
\hline
\end{tabular}

NS= non significant

*significant $(\mathrm{P}<0.01)$

Table III shows the clinical presentation of the patients. They commonly presented with sensory loss (60\%) and shooting pain (67\%). Bilateral partial nerve deafness was present in 3 cases $(20 \%)$ while complete deafness was manifested in one case $(6 \%)$.

Table III. Neurologic and audiometric findings in HSN1 patients

\begin{tabular}{ll} 
& HSN 1 patients (No 15) \\
\hline Shooting pain & $10(67 \%)$ \\
\hline Sensation: & \\
\hline Glove \& stock Hypothesia & $9(60 \%)$ \\
\hline Radicular hypothesia & $11(73 \%)$ \\
\hline Tendon Reflex (ankle reflex) & $2(13 \%)$ \\
\hline Muscle involvement & \\
\hline Feet only & $1(6 \%)$ \\
\hline Feet \& leg & $11(73 \%)$ \\
\hline Complications & $7(47 \%)$ \\
Audiogram & \\
\hline Bilateral partial nerve deafness & $3(20 \%)$ \\
Complete nerve deafness & $1(6 \%)$ \\
\hline
\end{tabular}

As regards to the SPTLC1 mutation, all patients with HSN1 showed mutant SPTLC1 when compared the control group (Figure 1). By sequencing of SPTLC1gene in the patients with HSAN I at exon 5 and exon 6 (Figure 2, Table IV), the point mutation (C133W) was the most prevalent one found in $9 / 15$ patients $(60 \%)$. In this mutation $\mathrm{G}$ replaces $\mathrm{T}$ at nucleotide position 399 , causing the substitution of cysteine $(C)$ with tryptophan (W) at amino acid 133. These patients were of the younger age group with severe clinical manifestation and severe ulceration. They also had a significant increase in both the serum nucleosome and serum CRP levels. While the second point mutation observed was $(\mathrm{C} 133 \mathrm{Y})$ found in $4 / 15$ patients $(27 \%)$. In this mutation A replaces $G$ at nucleotide position 398 , causing the substitution of cysteine $(C)$ with tyrosine $(\mathrm{Y})$ at amino acid 133. Those patients were of the older age group and had moderate clinical manifestations of HSN 1 with prominent hearing affection detected clinically and confirmed by audiometry. Lastly, patients with mild clinical manifestations $2 / 15$ patients (13\%) who presented with mild sensory loss, minimal ulceration and no hearing abnormalities had the mutation (V144D) in which A replaces $\mathrm{T}$ at nucleotide position 431, causing the substitution of aspartic acid for valine at amino acid 144 . Those two patients were unrelated and had a negative family history in contrast with the other patients who had a positive family history. No mutations were found in the samples of individuals in the control group. 


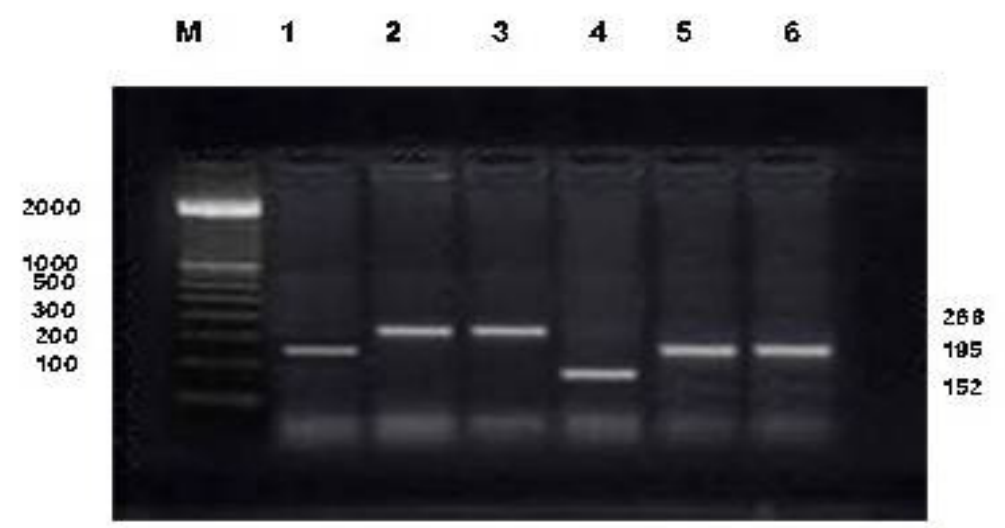

Figure 1. Gel electrophoresis of PCR product of the SPTLC 1 gene at exon 5 and exon 6 showing altered pattern in HSN1 patient compared to the control group

Lane $M \quad$ : Molecular marker of 100 bp ladder.

Lane 1, 5, 6 : Show the mutation of exon 5 (product 195 bp )

Lane 2,3 : Show the mutation of exon 6 (product 268 bp )

Lane 4 : Show the normal control (product $152 \mathrm{bp}$ ) 


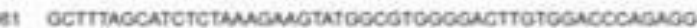

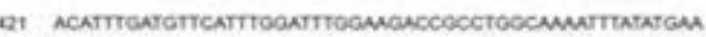

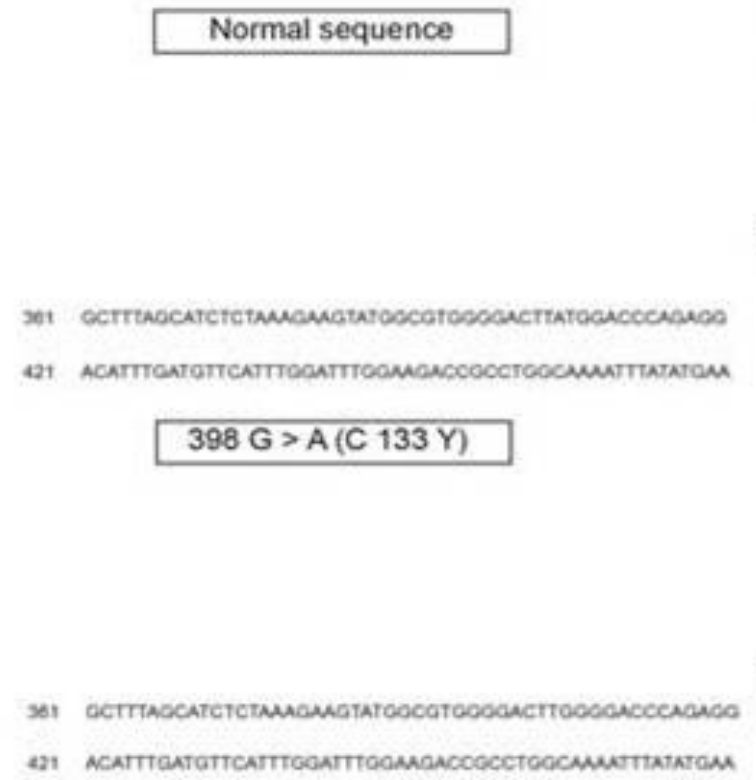

$399 \mathrm{~T}>\mathrm{G}(\mathrm{C} 133 \mathrm{~W})$

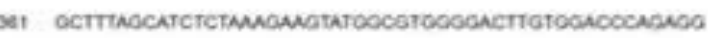

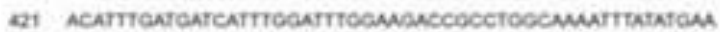

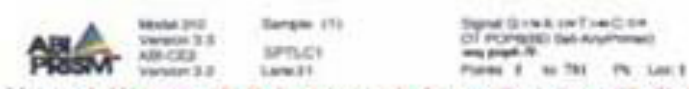

361 got tta goa tetct agaag tatggcgiggggactigtggacccagagg 411
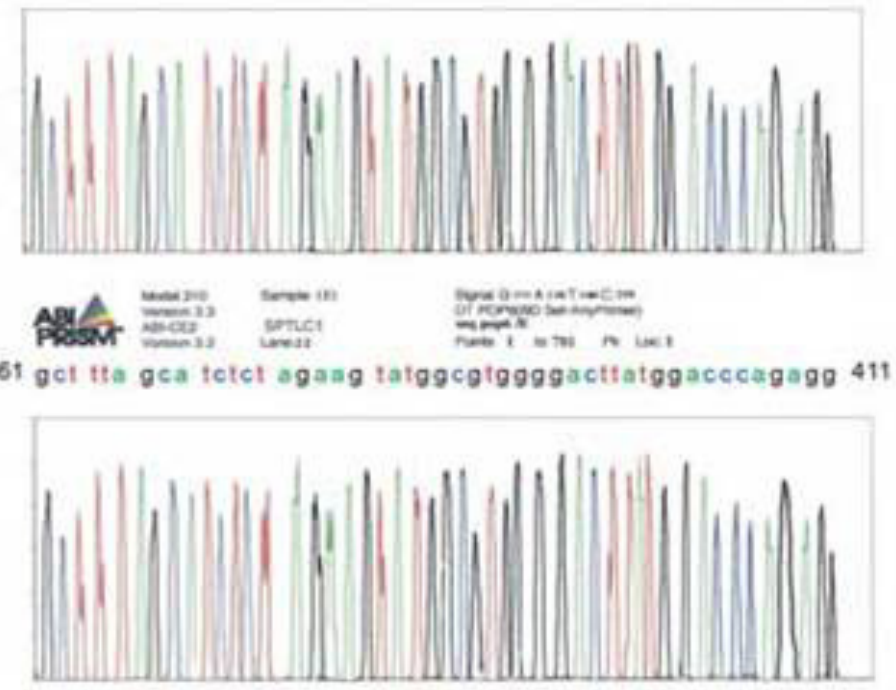

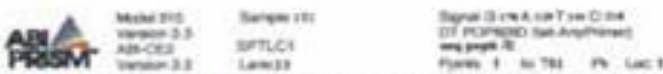

361 got tta gea tetet agaag tatggcgtggggactiggggacecagagg 411

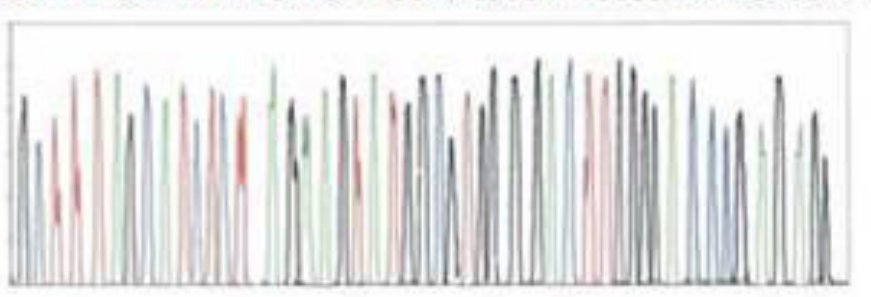

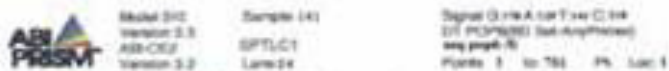

421 acattgatgatcottigattiggasaccgoctggcasalttatatgaa 469

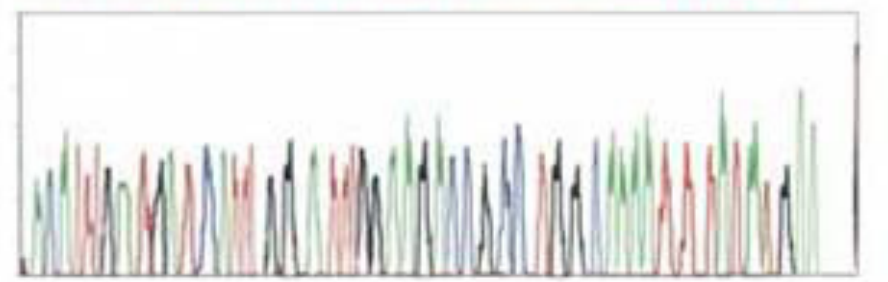

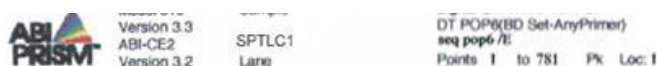

421 acattgatgttcatttggatttggaagaccgcctggcaaatttatatgaa 469

361 GCTTTAGCATCTCTAAAGAAGTATGGCGTGGGGACTTGTGGACCCAGAGG

421 ACATTTGATGTTCATTTGGATTTGGAAGACCGCCTGGCAAAATTTATATGAA

Normal control, exon 6

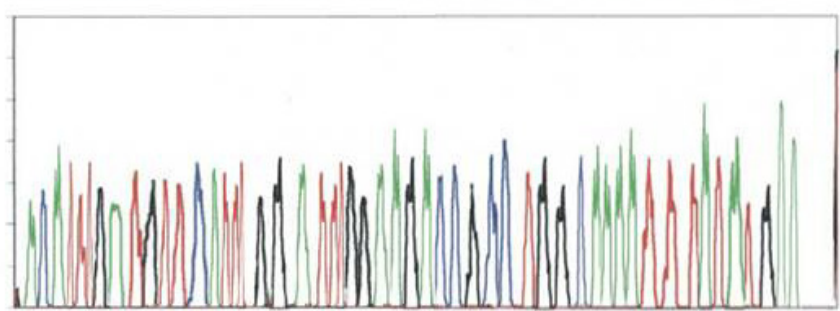

Figure 2. The nucleotide sequence (on the right) and the electrophoretogram (on the left) of SPTLC 1 gene at exon 5 and exon 6 containing the point mutation of the coding region. Point mutation occur and noted by change in the color of the nucleotide;

-The 1st row shows the normal nucleotide sequence at exon 5

-The 2 nd row shows (C133Y) mutation. The nucleotide changes from TGT to TAT at position 398.

-The 3rd row shows (C133W) mutation. The nucleotide changes from TGT to TGG at position 399.

-The 4th row shows (V144D) mutation. The nucleotide change from GTT to GAT at position 431

-The 5th row shows the normal nucleotide sequence at exon 6 
Table IV. Neurologic and audiometric findings in HSN1 patients with mutations in the SPTLC gene at exon 5 and exon 6

\begin{tabular}{llll} 
& HSN 1 & SPTLC1 Mutations & \\
Severe clinical presentation & $9(60 \%)$ & Ex 5 & C 133 W \\
\hline Auditory abnormalities & $4(27 \%)$ & Ex 5 & C 133 Y
\end{tabular}

The serum nucleosome level showed a significant increase in all HSN1 patients as compared to the control group (120.3 versus 25.2, $\mathrm{P}<0.01)$. Also, the serum CRP level showed a significant increase in HSN1patients as compared to the control group (76 versus $2.5, \mathrm{P}<0.01$ ), Table $\mathrm{V}$. Also in patients with the point mutation (C133Y) and (V144D) the serum levels of nucleosome and CRP were significantly elevated compared to the control group, however the increase was not statistically significant compared to the patients with (C133W) who manifested the highest elevation.

Table V. The serum nucleosome and CRP levels in HSNI patients and the control group.

\begin{tabular}{|c|c|c|c|c|}
\hline & \multicolumn{2}{|c|}{ Serum nucleosome AU } & \multicolumn{2}{|c|}{ CRP mg/L } \\
\hline & Control & Patients & Control & Patients \\
\hline Range & $1.2-34.9$ & $46-172$ & $0-4$ & Dec-96 \\
\hline Mean & 25.2 & 120.3 & 2.5 & 76 \\
\hline$\pm \mathrm{SD}$ & \pm 3.79 & \pm 6.85 & \pm 0.23 & \pm 4.51 \\
\hline $\mathbf{P}$ & $<0.01^{*}$ & & $<0.01^{*}$ & \\
\hline
\end{tabular}

*Significant $(P<0.05)$

$\mathrm{AU}=$ arbitrary units

DISCUSSION

Hereditary sensory neuropathy type 1 (HSNI) is a group of dominantly inherited degenerative disorders of the peripheral nerve in which sensory features are more prominent than motor involvement and the autonomic involvement is minimal. ${ }^{1,23}$

HSN1 form a dominantly inherited sensorimotor axonal neuropathy with variable sensorineural deafness. ${ }^{24}$ The HSN1 results from the mutation of a gene on chromosome 9 (922.1-22.3) that is involved in the production of an enzyme known as serine palmitoyletransferase (SPT). ${ }^{25}$

This study aimed to $\urcorner$ know the definite and severe clinical criteria of HSN1 as many patients face problems in working and quality of life. So, The clinical diagnosis of HSN1 was based on, a history of either chronic skin ulcers or painless injuries, gross sensory loss in all modalities, electrophysiological evidence of a chronic axonal neuropathy and molecular genetic study of the SPTLC1gene mutation. Severe, brief shooting pains were characteristic of HSN1 but were not a selection criterion. Sensorineural deafness was present in some members of some families.

The present study showed that the age of patients was in the 2 nd and 3 rd decade of life with male predominance. Ulcers affect the lower limbs more than the upper limb $(7 / 15-46.6 \%)$ and in more severe cases both lower and upper limbs were affected $(8 / 15$ - 53.4\%). Ulcers were found to affect younger age group (2nd decade) than older patients. This agrees with Auer et al, who reported in their study that older patients develop hearing loss while prominent distal neuropathy and ulceration were the presenting sign of younger patients. 3 Males were more severely affected than females. This was in agreement with Dawkins et al, who reported that the progression is usually more rapid in men with symptoms begining later in women than in men. ${ }^{26}$ This was also in agreement with reports by Henry et al, who stated that there is more severe symptoms and earlier onset in males, with significant motor involvement and reduced motor conduction velocities. ${ }^{27}$ Henry et al reported that the difference between males and females is fascinating and raises the possibility of hormonal influences or sex-linked genetic factors. ${ }^{28}$

Electrophysiological evidence of peripheral neuropathy proved by measuring the motor and sensory conduction velocity of the ulnar and lateral popliteal nerve were done in this study (Table II). There was a significant decrease in the motor and sensory conduction velocity of the lateral popliteal nerve in $(9 / 15)$ patients $(60 \%)$ compared to the control group. Those patients had trophic ulcers in the second metatarsal bone with shooting pain and muscle involvement. These finding agree with Khemissa et al, and Henry et al, who stated that there is a degeneration of motor neurons with secondary denervation atrophy and weakness of distal limb muscles. ${ }^{13,28}$ No significant difference was observed in nerve conduction velocity of ulnar nerve compared to that of control.

In this study hearing affection was detected in older age patients (4/15). Three patients manifested bilateral partial deafness while only one had complete nerve deafness. Deafness was evident clinically and confirmed by audiogram. This finding was in agreement with Dyck et al, who found that hearing loss 
may occasionally occur in HSN1 especially in the later onset or older age group. ${ }^{29}$ Also, Michaela et al, stated that in HSN1 patients, progressive hearing loss or even complete deafness may occur later in life. ${ }^{30}$

Molecular genetic study of the present work revealed that PCR analysis of the SPTLC 1 gene showed a mutation at exon 5 and 6 in the all affected individuals compared to the control group (Figure 1). Similar findings were observed by Dowkins et al, who reported that all affected individuals with HSN 1 show a definite or probable linkage to chromosome 9 at these two exons. ${ }^{12}$ The present study showed that, sequencing of SPTLC1 in the patients with HSAN1, revealed that the $(\mathrm{C} 133 \mathrm{~W})$ was the prevalent mutation found in $9 / 15$ patients $(60 \%)$. Those patients had severe clinical manifestation with severe ulceration accompanied with significant increase in the serum nucleosome and CRP. This is in agreement with Henry et al, who stated that, the high CRP protein may suggest an inflammatory neuropathic component but could be part of the C133W SPTLC1 phenotype observed in sever cases with ulceration. ${ }^{28}$ While the second mutation found was (C133 Y) in 4/15 patients (27\%). Those patients had moderate clinical manifestation of HSN1 with prominent hearing affection detected clinically and confirmed by audiometric findings.

Lastly, patients with mild clinical manifestation 2/15 patients (13\%) who presented with mild sensory loss, minimal ulceration and no hearing abnormalities had the mutation (V144D). Those two patients were unrelated and had a negative family history in contrast with the other patients who had a positive family history. No mutations were found in the samples of normal individuals. These findings agree with Dawkins et al, who reported that there are four missense mutations in the SPTLC1 gene (C133W, C133Y, V144D, and $\mathrm{G} 387 \mathrm{~A}$ ) responsible for the development of an inherited sensory neuropathy (HSN1).12 It is clear that sphingolipids are critical to neuronal function and mutations that perturb their synthesis; trafficking and degradation can be neurotoxic.31 Dawkins et al, reported that SPTLC 1 mutations are associated with increased de novo ceramid synthesis in individuals with HSN1. ${ }^{12}$ Ceramid functions as a bioactive lipid, modulating several biochemical and cellular responses to stress, including apoptosis, cell-cycle arrest, and cell senescence during neural tube closure. SPTLC1 mutations may prevent ceramide levels returning to normal after neural tube closure, resulting in gradual attrition of neurons over many years. ${ }^{32}$ Alternatively, Auer et al, suggested that, the mutant enzyme subunit protein may gain a toxic function. ${ }^{3}$ That is why the disease onset is not the same and this may be due to other environmental factors that trigger the onset of the disease.

Cell death is one essential factor which contributes to the functional lesion. ${ }^{18}$ The circulating DNA measured in serum may highly be predictive for the severity of underlying disease progression while the CRP is an indicator of inflammatory process. ${ }^{33}$
The present study showed that, serum nucleosomes and CRP were significantly elevated in HSN1 patients compared to the control $(p<0.01)$. Their levels were higher in patients with severe clinical presentation, massive ulceration and prolonged duration (early onset) than those with mild clinical manifestation. Significant better time to progression and overall survival was noted in patients who demonstrated lower levels .This finding agree with Geiger et al, who reported that, changes in nucleosomes concentration are expected to be relevant for the later outcome and reflect the degree of disease severity. ${ }^{34}$ The circulating nucleosomes is considered a non specific cell death measurer and, in blood, it can not be differentiated whether it simply reflect local or generalized inflammatory response. While Henry $\mathrm{H}$ et al, reported that, the high CRP protein may suggest an inflammatory neuropathic component accompanied patients with HSN1. ${ }^{28}$

\section{CONCLUSION}

The SPTLC-1 gene mutations play an important role in the pathogenesis and differential clinical presentation of the disease. C133W was the most commonly found mutation (in patients with severe illness). C133Y was found in patients with hearing loss (deafness) and V144D was the least common, mainly found in patients with mild clinical manifestations.

Thus it can be concluded that, in any case presenting with trophic ulcers and /or sensory loss with family history of HSN1 and/or consanguinity, clinical and neurological examination should be performed together with molecular genetic study of the SPTLC1 mutation either to prove or to rule out the diagnosis. Audiogram should also be carried out either to support the diagnosis or to sub-classify this disorder. it is also recommended to do pre-symptomatic detection of the SPTLC1 mutation for members with positive family history which may help to define an individual who is at high risk of developing HSN1 aiming at the use of prophylactic measures to prevent injuries arising from early loss of sensation . 


\section{REFERENCES}

1. Houlden H, Blake J, Reilly MM. Hereditary sensory neuropathies. Curr Opin Neurol 2004; 17:569-77

2. Andrea JL, Sam DL, Malcolm JC, Garth N, Seth L. Late-onset hereditary sensory neuropathy type1 due to SPTLC1 mutation. Clin Neurol Neurosurg 2006; 108:780-3

3. Auer-Grumbach M, De Jonghe P, Verhoeven $\mathrm{K}$, Timmerman V, Wagner K, Hartung HP, Nicholson GA. Autosomal dominant inherited neuropathies with prominent sensory loss and mutilations: a review. Arch Neurol 2003; 60:329-34

4. Hageman G, Hilhorst BG, Rozeboom AR. Is there involvement of the central nervous system in hereditary sensory radicular neuropathy? Clin Neurol Neurosurg 1992; 94:49-54

5. Garth A. Hereditary sensory neuropathy type 1. Clin Neurol Neurosurg 2005; 10:70-3

6. Wallace DC. Observations upon a predominantly sensory hereditary neuropathy. Proc Aust Assoc Neurol 1965; 3:1

7. Dubourg O. Phenotypic and genetic study of a family with hereditary sensory neuropathy and prominent weakness. Muscle Nerve 2000; 23:1508-14

8. Kwon JM, Elliott JL, Yee WC. Assignment of a second Charcot-Marie-Tooth type II locus to chromosome 3q. Am J Hum Genet 1995; 57:853-8

9. Bejaoui K, Wu C, Scheffler MD, et al. SPTLC1 is mutated in hereditary sensory neuropathy, type 1 . Nat Genet 2001; 27:1

10. Mandon EC, Ehses I, Rother J, van Echten G, Sandhoff K. Subcellular localization and membrane topology of serine palmitoyltransferase, 3-dehydrosphinganine reductase, and sphinganine $\mathrm{N}$-acyltransferase in mouse liver. J Biol Chem 1992; 267:11144-8

11. Nagiec MM, Baltisberger JA, Wells GB, Lester RL, Dickson RC. The LCB2 gene of Saccharomyces and the related LCB1 gene encode subunits of serine palmitoyltransferase, the initial enzyme in sphingolipid synthesis. Proc Natl Acad Sci USA 1994; 91:7899-902

12. Dawkins JL, Hulme DJ, Brahmbhatt SB, Auer-Grumbach M, Nicholson GA. Mutations in SPTLC1, encoding serine palmitoyltransferase, long chain base subunit-1, cause hereditary sensory neuropathy type I. Nat Genet 2001; 27:309-12

13. Khemissa B, Yoshikazu U, Satoshi Y, et al. Hereditary sensory neuropathy type 1 mutations confer dominant negative effects on serine palmitoyltransferase, critical for sphingolipid synthesis. J Clin Invest 2002; 110:1301-8

14. Verhoeven K, Coen K, De Vriendt E, et al. SPTLC1 mutation in twin sisters with hereditary sensory neuropathy type I. Neurology 2004; 62:1001-2

15. Hangtao W, Armando E and Myles C.

Enhanced denove ceramid generation through activation of serine palmitoyltransferase by P-glycoprotein antagonists. Molec Cancer Therap 2002; 1:719 - 26

16. David KP, Carton J, Shah AK, Meredith F, Uhlinger DJ, Hannun YA. Serine palmitoyltransferase regulates de novo ceramide generation during etoposide-induced apoptosis. J Biol Chem 2000; 275:9078-84

17. Hong KK, Cho HR, Ju WC, Cho Y, Kim NI. A Study on Altered Expression of Serine Palmitoyltransferase and Ceramidase in Psoriatic Skin Lesion. J Korean Med Sci 2007; 22: $862-7$

18. Dirnagl U, ladecola C, Moskowitz MA. Pathophysiology of ischemic stroke. Trends Neurosci 1999; 22:391-7

19. Sandra G, Stefan H, Petra Stieber, Gerhard F, Roland B, Jun M. Nucleosome as anew prognostic marker in early cerebral stroke. J Neurol 2007; 254:617-23

20. Holdenrieder S, Stieber P, Bodenmueller $\mathrm{H}$, Fertig G. Nucleosomes in serum as a marker for cell death .Clin Chem Lab Med 2001; 39:596-605

21. Thompson D, Milford-Ward A, Whicher JT. The value of acute phase protein measurement in clinical practice. Ann Clin Biochem 1992; 29:123-31

22. Holdenrieder S, Stieber P, Chan LYS, et al. Cell-free DNA in plasma and serum comparison of ELISA and PCR .Clin Chem 2005; 51:1544-6

23. KoK C, Kennerson ML, Spring Pj, Ing AJ, Pollard JD, Nicholson A. Locus for hereditary sensory neuropathy with cough and gastroesophageal reflux on chromosome 3 p22. Am J Hum Genet 2003; 73:632-7

24. Thomas, PK. Hereditary sensory neuropathies. Brain Pathol 1993; 3:157-63

25. McKusick VA. Mendelian Inheritance in Man. 12th ed. Baltimore: Johns Hopkins University Press, 1966.

26. Brahmbhatt JL, Auer-Grumbach S, Wagner M, et al. Exclusion of serine palmitoyltrans ferase long chain base subunit 2 (SPTLC2) as a common cause for hereditary sensory neuropathy. Neuromuscul Disord 2002; 12:656-8

27. Henry H, King R, Blake J, et al. Clinical, pathological and genetic characterization of hereditary sensory and autonomic neuropathy type 1 (HSAN I). Brain 2006; 129:411-25

28. Henry H, Charlton P, Sing H. Neurology and orthopedics. J Neurol Neurosurg Psychiatry 2007; 78:224-32

29. Dyck PJ. Neuronal atrophy and degeneration predominantly affecting peripheral sensory and autonomic neurons. In: Dyck PJ, 
Thomas PK, Griffin JW, Low PA, Poduslo JF, eds. Peripheral Neuropathy. 3rd ed.

Philadelphia; WB Saunders, 1993:1065-93.

30. Michaela A, Peter Jo, Kristien V, Vincent T, Klaus W, Hans P, Garth A. Autosomal Dominant Inherited Neuropathies With Prominent Sensory Loss and Mutilations. Arch Neurol 2003; 60:329-34

31. Alexander M, David T, Daniel C, et al. Mutant SPTLC1 dominantly inhibits serine palmitoyltransferase activity in vivo and confers an age-dependent neuropathy. Hum Mol Genet 2005; 14:3507-21

32. Homas H, Christina E, Silke A, Michael H, Stefan S, Alfred M, Gerhild V. Production of Ceramides Causes Apoptosis during Early Neural Differentiation in Vitro. J Biol Chem 2000; 275:30344-54

33. Rainer TH, Wang N, Metrewel C, Lo Y. Prognostic use of circulating plasma nucleic acid concentrations in patients with acute stroke. Clin Chem 2003; 49 :562-9

34. Geiger S, Holdenrieder S, Stieber P, Hamann GF, Bruning R, Ma J. Nucleosomes in serum of patients with neuropathic pain. Cerb Vas Dis 2006; 21:32-7

24. Thomas, PK. Hereditary sensory neuropathies. Brain Pathol 1993; 3:157-63

25. McKusick VA. Mendelian Inheritance in Man. 12th ed. Baltimore: Johns Hopkins University Press, 1966.

26. Brahmbhatt JL, Auer-Grumbach S, Wagner M, et al. Exclusion of serine palmitoyltrans -

ferase long chain base subunit 2 (SPTLC2) as a common cause for hereditary sensory neuropathy. Neuromuscul Disord 2002; 12:656-8

27. Henry $\mathrm{H}$, King $\mathrm{R}$, Blake J, et al. Clinical, pathological and genetic characterization of hereditary sensory and autonomic neuropathy type 1 (HSAN I). Brain 2006; 129:411-25

28. Henry H, Charlton P, Sing $H$. Neurology and orthopedics. J Neurol Neurosurg Psychiatry 2007; 78:224-32

29. Dyck PJ. Neuronal atrophy and degeneration predominantly affecting peripheral sensory and autonomic neurons. In: Dyck PJ, Thomas PK, Griffin JW, Low PA, Poduslo JF, eds. Peripheral Neuropathy. 3rd ed. Philadelphia; WB Saunders, 1993:1065-93.

30. Michaela A, Peter Jo, Kristien V, Vincent T, Klaus W, Hans P, Garth A. Autosomal Dominant Inherited Neuropathies With Prominent Sensory Loss and Mutilations. Arch Neurol 2003; 60:329-34

31. Alexander M, David T, Daniel C, et al. Mutant SPTLC1 dominantly inhibits serine palmitoyltransferase activity in vivo and confers an age-dependent neuropathy. Hum Mol Genet 2005; 14:3507-21

32. Homas H, Christina E, Silke A, Michael H, Stefan S, Alfred M, Gerhild V. Production of
Ceramides Causes Apoptosis during Early Neural Differentiation in Vitro. J Biol Chem 2000; 275:30344-54

33. Rainer TH, Wang N, Metrewel C, Lo Y. Prognostic use of circulating plasma nucleic acid concentrations in patients with acute stroke. Clin Chem 2003; 49 :562-9

34. Geiger S, Holdenrieder S, Stieber P, Hamann GF, Bruning R, Ma J. Nucleosomes in serum of patients with neuropathic pain. Cerb Vas Dis 2006; 21:32-7 